SOI: $\underline{1.1 / \mathrm{TAS}}$ DOI: $10.15863 / \mathrm{TAS}$

International Scientific Journal

\section{Theoretical \& Applied Science}

\author{
p-ISSN: 2308-4944 (print) e-ISSN: 2409-0085 (online)
}

Year: $2017 \quad$ Issue: 12 Volume: 56

Published: 30.12.2017 http://T-Science.org
Sabuhi Tahir Huseynov doctoral student of the department

"Customs and international trade" of the Azerbaijan State Economic University, Baku, Azerbaijan Republic nauka-xxi@mail.ru

SECTION 19. Management. Marketing. Public administration.

\title{
THE STRATEGIC FEATURES OF EXTERNAL TRADE MANAGEMENT BY CONSUMER GOODS IN MODERN CONDITIONS
}

Abstract: The the strategic features of managing foreign trade in consumer goods in modern conditions are examined in the article. The role of consumer goods in the international division of labor and world markets, their movement and management processes is analyzed with this purpose. The essence of the processes and stages in the development of the company's exit strategy to the market of external consumers is disclosed. The strategic features of foreign trade management are considered. The importance of strategic management of consumer goods is grounded. The need to ensure efficiency in the management of foreign trade was noted. The recommendations and proposals on the problems are given at the end of the article.

Key words: management of foreign trade, consumer goods, the effectiveness of managing foreign trade in consumer goods, the strategic features of foreign trade management, the role of consumer goods in world markets.

Language: Russian

Citation: Huseynov ST (2017) THE STRATEGIC FEATURES OF EXTERNAL TRADE MANAGEMENT BY CONSUMER GOODS IN MODERN CONDITIONS. ISJ Theoretical \& Applied Science, 12 (56): 239-242.

Soi: http://s-o-i.org/1.1/TAS-12-56-39 Doi: crossef https://dx.doi.org/10.15863/TAS.2017.12.56.39

\section{СТРАТЕГИЧЕСКИЕ ОСОБЕННОСТИ УПРАВЛЕНИЯ ВНЕШНЕЙ ТОРГОВЛИ ПОТРЕБИТЕЛЬСКИМИ ТОВАРАМИ В СОВРЕМЕННЫХ УСЛОВИЯХ}

Аннотация: В статье рассматривается стратегические особенности управления внешней торговли потребительскими товарами в современных условиях. Анализируется процессы формирования стратегии по организациям управленческой системы во внешней торговле с расширением перечня конкурентоспособных потребительских товаров. Раскрыта сущность прочессов и этапов по выработке стратегии выхода фирмы на рынок внешних потребителей. Рассматривается стратегические особенности управления внешней торговлей. Раскрывается важность эффектиной организаџии управления внешней торговлей потребительскими товарами. Оченень роль потребительских товаров на мировых рынках в условиях расширения глобальных тенденций.

Ключевые слова: управление внешней торговлей, потребительские товары, эффективность управления внешней торговлей потребительских товаров, стратегические особенности управления внешней торговлей, роль потребительских товаров на мировых рынках.

\section{Introduction}

Отметим, что по мере расширения внешнеторговых связей возникает потребность в новых инструментах для оптимизации участия страны в международной специализации, ограждения национальной экономики от влияния негативных явлений в мировой торговле. Экономико-организационных управления внешней $\begin{array}{lrr}\text { потребительскими } & \text { товарами } & \text { охватывает } \\ \text { следующие задачи: } & & \\ \text { - обеспечить глубокое изучение особенности } \\ \text { управления } & \text { внешней } & \text { торговлей }\end{array}$ потребительскими товарами;

- разработать методические приемы и методы управления внешней торговлей потребительскими товарами; 
- определить ресурсное обеспечение перестройки структуры управления внешней торговлей потребительскими товарами;

$$
\text { провести структурный анализ }
$$
современного состояния системы управления внешней торговлей;

- совершенствовать механизм управления внешней торговлей;

определить пути повышения эффективности экспортно-импортных операций и т.д.

\section{Materials and Methods}

В современных условиях развития рыночной экономики существующие принципы полностью не могут обеспечить достижение поставленных целей внешней торговли. Необходимо во многом их трансформировать и выработать новые применительно к отсутствию государственной монополии на внешнюю торговлю и намеченной открытости экономики. Внешнеэкономическая деятельность является основным каналом реализации интеграционных мероприятий. Это положение наряду с общим повышением роли и значения данной сферы в общественном воспроизводстве предъявляет повышение требования к системе управления, делает необходимым последовательное совершенствование с целью повышения ее эффективности, создания наиболее благоприятных внешних условий для интенсификации хозяйственного развития и взаимного сотрудничества [1]. Стратегическое управление - это прежде всего определенная философия или идеология бизнеса и менеджмента. При этом каждым отдельным менеджером оно понимается и реализуется в значительной мере по-своему. Требуются огромные усилия и большие затраты времени и ресурсов для того, чтобы фирма начала осуществлять процесс стратегического управления, включая процесс стратегического планирования и разработку долгосрочных планов [2].

В системе управления внешней торговлей важнейшей составляющей стратегического управления является выработка стратегии выхода фирмы на рынок внешних потребителей, включающий несколько этапов:

$\square$ стратегия контрольной точки; стратегия «снятия сливок»;

$\square$ стратегия,

основанная

на воспринимаемой ценности товара;

$\square$ стратегия реализации группы товара; факторы, влияющие на выбор стратегии;

$\square$ учет затрат на производство и реализацию товара;

$\square$ жизненный цикл товара, изменение рыночной стратегия; исследование потенциальных возможностей фирмы при работе на внешнем рынке [3].

Следует подчеркнуть, что при выборе стратегии выхода на внешний рынок фирма должна обязательно учесть ряд факторов, значительно влияющих на рынок того или иного товара, к числу которых можно отнести: макроэкономические показатели и характеристика страны; налогообложение и таможенное регулирование; внешне-торговая политика. Особое место при выборе стратегии занимает учет затрат на производство и реализация продукции фирмы на рынке. При проведении любой стратегии на любом рынке фирма в конечном итоге должна получить прибыль, поэтому построение стратегии невозможна без рассмотрения величины и структуры затрат на производство. Последователь - это компания, которая стремится сохранить свою долю рынка, используя роль двойника. Компания оперирующая в нище, обслуживает небольшие сегменты рынка, оставляющиеся вне сферы внимания крупных фирм [4]. Поскольку каждая организация имеет собственную меру эффективности одного и того же проекта, все участники проекта обычно осуществляют собственную автономную его оценку [5;6].

Очень важно признать тот факт, что для того, чтобы быть эффективным, виды деятельности, связанные с продажами, должны осуществляться в контексте общего стратегического маркетингового плана. Только в этом случае можно гарантировать, что усилия по продажам будут соответствовать, а не противоречить другим маркетинговым действиям. В связи с этим стратегии и тактики продаж могут быть только выбраны и реализованы в рамках общих задач компании и процессов ее стратегического планирования [7]. В то время стратегические планы компаний должны разрабатываться так, чтобы не только оставаться целостными в течении длительного периода времени, но и быть динамично гибкими, чтобы при необходимости можно было бы осуществить их модернизацию. Общий стратегический план следует рассматривать как программу, которая направляет деятельность фирмы в течении длительного периода [8;9].

Отметим также важность изучения конъюнктуры рынка в процессах подготовки стратегии фирмы на выход во внешний рынок, так как в стратегию управления при выходе фирмы на внешний рынок входит и исследования по изучению конъюнктуры рынка [10]. Высокая эффективность работы по изучению конъюнктуры, проблем и долговременных тенденций развития рынка возможна только при 
принципов целенаправленности, комплексности, систематичности.

Необходимо также определить уровень конкретизации анализа и прогноза, который намечается провести. На основе такой предварительной работы уточняются объем и характер необходиых материалов. Стратегическое рыночное управление носит предупреждающий, устремляющий в будущее характер. Стратегия не должна подчиняться среде, не должна воспринимать ее как данность. Они обязаны упреждать возможные перемены, влиять на происходящие внутри и вне компании изменения [11].

\section{Conclusion}

Проведенные теоретико-методологические и практические исследования в области совершенствования системы управления внешней торговли потребительскими товарами позволяет сделать следующих выводов:

- основные направления совершенствование системы управления внешней торговлей должны базироваться на объективных принципах управления и на конкретных функциях управления, включая систему управления и хозяйствующую деятельность;

- система управления внешней торговлей должна руководствоваться нормами международного и внутреннего права с учетом различных принципов международных организаций и объединений;

- система упралвения внешней торговлей должна формироваться с учетом факторов усиления конкуренции и определение конкурентным преимуществом;

- основным структурным образованием системы управления внешней торговлей выступают совместные предприятия различной формы, построенные на принципах интеграции, координации и кооперации;

- в условиях современной рыночной экономики система управления внешней торговлей, включая основные ее субъекты, должна быть, построена с учетом как «старой», так и новой конкуренции, особенно включая вопросы повышения эффективности системы управления внешней торговлей потребительскими товарами.

- стратегия управления внешней торговлей потребительскими товарами должны базироваться: на стратегии контрольной точки насыщения; последовательном привлечении разных сегментов рынка; на стратегии восприимчивости ценности потребительского товара; на стратегии эффективности и результативности;

- стратегия управления должна строиться с учетом основных элементов структур управления бизнес - единиц и инвестиционных проектов, международного маркетинга и менеджмента, международного публичного и частного права, особенностей конъюнктуры рынка и управления продажами;

- новшеством в системе управления внешней торговли потребительскими товарами должно быть внедрения внешней торговли управления с использованием методов позиционирования, принципов международного инвестирования с учетом современных подходов финансирования, дискретного распределения и дисконтирования международных инвестиционных проектов, оценкой международного бизнеса, а также учета инфляционных процессов и т.д.

\section{References:}

1. Glushchenko V.V., Glushchenko I.I. (2000) Razrabotka upralvencheskogo resheniya. Prognozirovaniye-planirovaniye. Teoriya prognozirovaniya eksperimentov. M.: NPSH. Kryl'ya. 2000.-351 p.

2. Samedov A.G., Nazarov K.P. (2003) Vneshnyaya i vnutrennyaya sreda ekonomicheskoy strategii firmy. Baku.: MarsPrint. 2003.-170 p.

3. (2001) Vneshneekonomicheskaya deyatel'nost' predpriyatiya. Pod red. L.Ye.Strovskogo. M.: YUNITI. 2001. -p. 101-117.
4. Kotler F. (2001) Marketin menedzhment. Ekspress-kurs. SPb.:Piter. 2001.-211 p.

5. Samedov A.G., Safarova V.T. (2002) Upravleniye kommercheskoy deyatel'nost'yu torgovykh firm. Baku.: Mars-Print. 2002. -120 p.

6. (2008) Upravleniye sub"yektami rynka (teoriya i praktika). Pod obshch. red. prof. A.G.Samedova. Moskva-Baku.: Mars-Print. 2008.-684 p. 


\begin{tabular}{|c|c|c|c|c|c|c|}
\hline Impact Factor: & $\begin{array}{l}\text { ISRA (India) } \\
\text { ISI (Dubai, UAE } \\
\text { GIF (Australia) } \\
\text { JIF }\end{array}$ & $\begin{array}{l}=1.344 \\
=0.829 \\
=0.564 \\
=1.500\end{array}$ & $\begin{array}{l}\text { SIS (USA) } \\
\text { PИНЦ (Russia) } \\
\text { ESJI (KZ) } \\
\text { SJIF (Morocco) }\end{array}$ & $\begin{array}{l}=0.912 \\
=\mathbf{0 . 2 0 7} \\
=\mathbf{3 . 8 6 0} \\
=\mathbf{2 . 0 3 1}\end{array}$ & $\begin{array}{l}\text { ICV (Poland) } \\
\text { PIF (India) } \\
\text { IBI (India) }\end{array}$ & $\begin{array}{l}=6.630 \\
=1.940 \\
=4.260\end{array}$ \\
\hline
\end{tabular}

7. Dzhobber D., Lankaster Dzh. (2002) Prodazhi i upravleniye prodazhami. M.: YUNITI-DANA. 2002.-622 p.

8. Mishin V.M. (1995) Mirovaya ekonomika i mezhdunarodnyye ekonomicheskiye otnosheniya. M.:MNEPU. 1995.-p. 27-30.

9. Rumyantsev E.P. (2005) Obshcheye upravleniye organizatsiyey (teoriya i praktika). M.: INFRA-M, 2005.-284 p.
10. Kamtseva N.G., Polyakov V.A. (2006) Marketingovyye issledovaniya. M.: Vuzovskiy uchebnik. 2006. -48 p.

11. Aaker D. (2007) Strategicheskoye rynochnoye upralveniye, per. s angl. SPb.:Piter.: 2007.-p. 30-31. 